\title{
An experimental study of ultrasonic-assisted hot incremental Ti-6Al-4V sheet metal forming
}

Saeed Amini ( $\nabla$ s.amini@me.iut.ac.ir)

Mechanical Contractors Association of BC: Mechanical Contractors Association of British Columbia Mahmoud Farzin

Isfahan University of Technology

Aminollah Mohammadi

Isfahan University of Technology

\section{Research Article}

Keywords: Ultrasonic, Hot Incremental forming, Impurities, Formability, Quality of surface, Ti-6Al-4V, Reduction of transition temperature

Posted Date: April 19th, 2021

DOI: https://doi.org/10.21203/rs.3.rs-348898/v1

License: (c) (1) This work is licensed under a Creative Commons Attribution 4.0 International License. Read Full License 


\section{Abstract}

The use of ultrasonic vibration in the manufacturing process has significant and different effects. Studying the effect of longitudinal ultrasonic vibrations on the performance of the electrical hot incremental forming (EHIF) process of Ti-6Al-4V sheets was the main purpose of this paper. In this new technique, ultrasonic vibrations with a high frequency and a low axial amplitude were combined using an electrical heater device. These devices were designed, manufactured carefully and used to perform the sheet incremental forming process at elevated temperatures. This system consisted of different parts including a mechanism attached into the chuck of the CNC machine to give the rotary motion; also, the ultrasonic power was sent to the vibratory tool. By changing some input variables including feed-rate, step-down and current, output features such as quality surface, maximum forming angle, and levels of impurities were investigated in both conventional-(EHIF) and ultrasonic-assisted-(EHIF) processes. The obtained results showed that ultrasonic assistance could increase the quality surface and decrease the impurities; also, XRD (X-ray diffraction) phase analysis showed that $\beta$ phase (BCC structure) was increased due to the reduced transition, thus improving formability.

\section{1-introduction}

Titanium alloys are common in aerospace applications, mainly due to their high strength-to-weight ratio. $\mathrm{Ti}-6 \mathrm{Al}-4 \mathrm{~V}$ is one of the most famous members of this family; meanwhile, there are many problems in forming Ti-6Al-4V due to lack of formability and spring back. One of the new methods used for forming this alloy in batch production is (EHIF). It has, however, some drawbacks such as low quality of the manufactured parts, low-level of surface quality, and the negative effect of impurities. Ultrasonic method can provide good effects in the manufacturing process. To the best of authors' knowledge, there is no report on the effect of the application of ultrasonic vibrations on the hot incremental forming of the Ti$6 \mathrm{Al}-4 \mathrm{~V}$ sheet. So, this study was conducted to combine the ultrasonic effect with the hot incremental forming of the Ti-6Al-4V sheet. More specifically, this paper considered the effect of ultrasonic vibrations with a longitudinal mode on the hot incremental forming of sheet. In the following, a number of former studies are reviewed.

At first, Blaha and Longenecker[1],in1955, introduced the use of superimposed ultrasonic vibration during metal forming. They investigated the ultrasonic vibration effect on the Zinc crystal behavior. Many research studies have already shown the influence of ultrasonic vibration as a high frequency low amplitude mechanical wave on different manufacturing processes such as wire drawing[2], grinding[3], forming [2, 4, 5], casting[6],machining[7]. The results have shown some positive effects, such as reduction of the forming force, flow stress, interface friction, and improvement of the surface quality and process efficiency. These effects could be attributed to the following mechanisms: acoustic softening [1] acoustic hardening[8], thermal softening, friction reduction and stress superposition. thermal softening, friction reduction and stress superposition. The two former mechanisms show changes in material properties, while the third one displays changes in the interface friction; the last mechanism can lead to changes in the loading condition. Acoustic softening is described as the reduction of flow stress while 
superimposing ultrasonic vibration, whereas acoustic hardening refers to increasing the flow stress beyond the normal condition after stopping ultrasonic vibration. Also, these acoustic effects depend on ultrasonic parameters and material properties. Different materials show different behaviors. Table one shows the mechanical properties of the material (Ti-6Al-4V) studied in this research.

Table 1

Ti-6Al-4v mechanical properties From Chen et al.[9]

\begin{tabular}{|llll|}
\hline Temp $\left({ }^{\circ} \mathrm{C}\right)$ & Young's modulus (GPa) & Poisson's ratio & Density $\left(\mathrm{kg} / \mathrm{m}^{3}\right)$ \\
\hline 21.11 & 117.21 & 0.31 & 4430 \\
204.44 & 106.87 & 0.31 & 4430 \\
426.67 & 95.15 & 0.31 & 4430 \\
648.89 & 82.72 & 0.31 & 4430 \\
\hline
\end{tabular}

\section{2 - Experimental Setup And Equipment}

Figure 1 shows the experimental setup applied in this work. The main equipment included eight parts: the CNC Milling machine, forming tool, sheet blank, blank holder, AC power source, Ultrasonic Generator, Transducer and horn. As shown in figure 2, after preparation of the vibratory forming tool, a mechanism giving both ultrasonic vibrations and transferring high amperage electricity to the forming tool was devised, fabricated and carried out on the CNC milling machine to develop the EHIF-ultrasonic assisted process; also, a 3-axis CNC mill machine was applied as a platform. The sheet blank was tightly fixed by a clamp. A simple tool with a hemispherical end formed the sheet at high temperatures (range of 500$600^{\circ} \mathrm{C}$ ). The tool was made from high-speed steel (HSS) and mounted on the horn. Also, a thermometer was used to measure and control the temperature at the interface of the tool and sheet.

An alternative electric current passed through a high-pressure transformer and then went through the tool and sheet. The transformer reduced the voltage (the input voltage was $220 \mathrm{~V}$ ) and delivered a high amperage Current, i.e., around 100-200 A, and a voltage of about $1-1.5 \mathrm{~V}$.

Therefore, a contacted small zone between tool and work piece started to heat up due to the maximum electrical resistance, according to the Ohm's law. The amount of the generated heat was proportional to the electrical resistance.

At the same time, longitudinal mechanical vibrations were applied to the instrument.

On the other hand, the Ultrasonic Generator stimulated the transducer and vibrated simultaneously due to tool.

\subsection{US vibration device}


Ultrasonic vibrations can be applied either to the part or to the tool. In the proposed design, ultrasonic vibrations were applied to the tool. To apply ultrasonic vibrations to a forming tool, a mechanism which could rotate ultrasonic transducer was designed and attached to the spindle of the CNC machine. In this mechanism, a perpendicular gear box was used to transmit the torque from spindle to transducer, as shown in Figure 2. Experiments were performed by a CNC milling machine (FP4ME) made by Tabriz Company. In this study, an Ultrasonic generator with the frequency of $20 \mathrm{kHz}$ and power of $1 \mathrm{~kW}$ was used to convert the frequency of the city electricity current to high ones. Figure 2 shows the transmission system in this design; the rotary motion generated by machine spindle was transmitted to the shell (the cover of transducer) by a timing belt, and bearings made the rotary freedom by which the ultrasonic transducer could be both rotated and clamped.

The forming tool was made of stainless steel; its mechanical properties are shown in Table 2.

Table 2 .mechanical properties of forming tool

\begin{tabular}{cc}
\hline Density & $\square=7890 \mathrm{Kg} /$ \\
Young modulus & $\mathrm{E}=202 \mathrm{e} 9 \mathrm{~N} /$ \\
Poisson's ratio & $\square=0.29$ \\
\hline
\end{tabular}

The transducer was driven by an ultrasonic generator (power supply). Electrical impulses generated by generator were sent to the piezoelectric rings (the most important part of an ultrasonic traducer) and converted to high frequency mechanical vibrations due to the piezoelectric effect.

a forming tool; it should be noted that forming tool must have a resonance frequency similar to that of transducer until the resonance phenomenon would happen and the maximum vibration amplitude could be achieved.

For this purpose, we had to do modal analysis. In this study, modal analysis was performed via the ABAQUS software. Then the geometry of the forming tool was changed for every modal analysis (Fig. 3 )

In fact, by performing the modal analysis, different mode shapes of the forming tool were obtained; by changing the dimensions of the forming tool, mostly length, the longitudinal mode shape of the forming tool was dropped in the desired domain ( $20 \pm 0.7 \mathrm{kHz})$. Eventually, after some analysis, the frequency of $20,602 \mathrm{HZ}$ was found for the forming tool.

\section{Results And Discussion}

In this research, based on a previous experiment and studies performed by researchers, a popular geometry was selected; parameters such as surface roughness, effect of impurities, and the maximum angle of forming in the two modes (with and without ultrasonic assistance) were compared.

\subsection{Work piece geometry and tests parameters}


To study the ultrasonic effect on the process parameters, the variable of wall angle conical frustum (VWACF) geometry was chosen and formed. One of the most important parameters serving as a measure of formability in ISF is the maximum wall angle that can be achieved before failure during forming (VWACF). In general, this angle can be found by forming several constant wall angle conical frustums (CWACF), which may require a large number of tests. An alternative approach is to form a (VWACF) in which the wall angle is gradually increased as forming incrementally progresses. Because of the popularity of this shape in ISF, it was selected to study the maximum wall angle. Figure 4 shows a crosssection view of this work piece, where $\mathrm{Q}_{1}$ and $\mathrm{Q}_{2}$ are the minimum and maximum wall angles, equal to $20^{\circ}$ and $80^{\circ}$, respectively.

After choosing the incremental step-down, tool diameter and tool path, a G-code program was needed to run the CNC machine; this was generated using the Power MILL commercial package. In order to have a smooth movement of tool with a specific step in forming the sheet, the program adjustment was done in a spiral mode; the penetration step of the tool in each rotation was according to DOE, as represented in table 3(the process parameters and the level used in EHIF).

Table 3. The process parameters used in the EHIF with ultrasonic-assisted

levels Level1 Level2 Level3

$\overline{\text { Voltage(volt) } \quad 150 \quad 190 \quad 300}$

Step-down $(\mathrm{mm}) \quad 0.1 \quad 0.2 \quad 0.3$

Feed-rate(mm/min) $600 \quad 900 \quad 1200$

The generated tool path and a photograph of the final workpieces are shown, respectively, in Figure. 5(ab).

\subsection{Investigation of the ultrasonic effect on the EHIF processing parameters}

There are many influential parameters on the quality of the specimens produced by EHIF. Because of the complexity of the ultrasonic effect on the EHIF process parameters, this study investigated this effect by considering some of them separately.

\subsubsection{Influence of the ultrasonic vibration on the reduction Impurities}

Ultrasonic vibrations seem to reduce the volume of impurities in several ways. First, their lubricating effect can reduce the amount of lubricant, such as $\mathrm{MoS}_{2}$ (molybdenum sulfide powder). Second, due to their heating effect on the inter granular, less electricity is required; so, the work surface is less heated and its impurities are reduced; on the other hand, the impurities are decreased by reducing the penetration into the surface of the parts. Figure 6 shows the results of the ultrasonic power effect on the increase of temperature in the sheet. This photo was taken by Testo 882 thermal imaging camera when there was no current in the circuit and the ohm's law was omitted temporarily; it showed that with $1 \mathrm{KW}$ ultrasonic 
power, the temperature of the workpiece was raised to about $100^{\circ} \mathrm{C}$. This caused the reduction of the current heating the sheet.

Then, by establishing a high pressure electric current flow, the workpiece was heated up to about $600 \mathrm{co}$, according to figure 7 .

According to Figure 8, parts of the sample were separated after forming and the EDAX (Energy-dispersive $X$-ray) analysis was performed. The results showed that the impurities were decreased significantly.

Figure 9 shows the results.

As can be seen, the impurity content of the molybdenum sulfide powder $\mathrm{MoS}_{2}$ was decreased from about $8.8 \mathrm{k}$ to about 1 ; also, oxygen was reduced from about $1.92 \mathrm{k}$ to $0.94 \mathrm{k}$.

In this study, the amount of current passing through the sheet has been usually expressed to be in the range of 180-220 amps. One reason for this is that the small contact surface causes the electrical resistance to be high in the early moments; however, with increasing the temperature, the electrical resistance was raised; this was related to changing the electrical conductivity of Ti-6Al-4V, according to its properties.

On the other hand, during gradual completion of the shape and its middle cavity deepening, we would face the thermal accumulation phenomenon; so, if the process were continued with an initial constant current, the temperature would increase exponentially and in an uncontrolled manner; in order to better control the process and improve the quality of parts, continuous and online control of the current during the process is necessary. Figure 10 indicates species that have become defective due to heat accumulation, despite reaching the maximum angle.

\subsubsection{Influence of the Ultrasonic vibration on roughness surface}

Due to the severe friction contact between the tool and sheet, we had to use a lubricant; because of the high temperature and high pressure in the forming zone, the best choice was the $\mathrm{MoS}_{2}$ powder. This has also been confirmed in the previous research[10]. On the other hand, $\mathrm{MoS}_{2}$ powder has can become clumpy, adhering to the tool head at high temperatures. According to the author's research [11], this could cause the surface of the sheet to be peeled and very rough, as shown in figure11(a).

In comparison with the normal EHIF process, one of the benefits of using ultrasonic waves is reaching a better surface quality due to better and easier movement of the tool on the sheet and the reduced friction. On the other hand, this rules out the sticking of powder to the tool; this can have a significant effect on the improvement of the surface quality.

To measure the effect of the process parameters on the surface roughness of the specimen, according to DOE, three levels of step-down were selected. A Mitutoyo surface roughness measuring machine (SURFTEST SJ-210 model) was then used to record the surface profile and calculate the average roughness, i.e., Ra. 
The effect of step-down on the surface roughness in the normal EIHF process and the ultrasonic-assisted process was studied through forming at three different step-downs: 0.1-0.2\&0.3; the results are displayed in figure 13. This showed that UV could have a significant effect on the reduction of the surface roughness.

\subsubsection{Ultrasonic effect on the forming angle}

According to figure.13, the maximum angle of forming was obtained from equation 1 ; in this research, the effect of the feed-rate \&UV on the forming angle was studied simultaneously.

$$
\phi_{\max }=\arccos \left(\frac{\mathrm{y}_{1}-\mathrm{h}_{\mathrm{c}}}{\mathrm{R}}\right)
$$

\section{Equation 1 The formula of obtaining the angle of the rupture depth}

The results showed that, the value of the maximum forming angle was increased about $20 \%$ by using ultrasonic-assisted process, comparing with normal EIHF. This happened by setting a constant pitch equal to 0.1 , figure. 14 shows that the maximum forming angle increased about $6 \sim 8 \%$ by changing the speed in both levels (level 1 to 2 , and 2 to 3 ). This gradual increase of the maximum forming angle with heat accumulation could be described. The increase of feed prevented heat accumulation, oxidization and brittleness of the specimen at the bottom of it.

In the ultrasonic-assisted mode, the maximum forming angle was increased significantly, with better lubrication condition; so heating-up in the intergranular could be regarded as this reason for this phenomenon; on the other hand, according figure 15, XRD phase analysis showed that $\beta$ phase (BCC structure) was increased significantly (it was the best formable Ti-6Al-4V phase), while the phase transformation temperature was $9900^{\circ}$; this showed the ultrasonic wave effect on the reduction of phase transformation activation energy; the influence of mechanical stimulation on the reduction of transition temperature has been confirmed in a previous research carried out by Tian et al [12] and C.zao et al[13] .

\section{5- Conclusions}

This study presented the design and fabrication of an ultrasonic-assisted vibration forming tool with a low amplitude; it was shown that rotary and vibrating motions as well as the desired path geometries could be simultaneously applied to form the Ti-6Al-4V sheets at elevated temperatures. Vibrations were generated by an ultrasonic transducer with a frequency of $19.65 \mathrm{kHz}$. This process was called ultrasonicassisted EHIF. The results of the study can be summarized as follows:

1. 1.The device could effectively heat up the sheet to the required temperatures for EHIF, as well as reducing friction.

2. 2. Longitudinal vibration with $1 \mathrm{~kW}$ power heated-up the sheet about $100 \mathrm{c}$ 。 
3. 3. Ultrasonic effect caused the amount of impurity to be reduced significantly.

4. 4.In EHIF, any increase in some process parameters, such as wall angle and step size, could decrease the formability of the blanks. However, ultrasonic vibrations reduced the slope of this reduction.

5. 5. Surface roughness of the sheet was significantly improved with ultrasonic vibrations.

6. 6. XRD phase analyses showed that $\beta$ phase (BCC structure) and hence, formability was increased significantly.

\section{Declarations}

- Ethical approval: No applicable

- Consent to participate: All authors agreed to participate in this research

- Consent for publication: All authors have read and agreed to the published version of the manuscript.

- Availability Data and Material: Not applicable

- Authors are responsible for correctness of the statements provided in the manuscript.

- Authors Contribution: " All authors have contributed equally to the work"

- Conflict of interest:" The authors declare that they have no potential conflict of interest in relation to the study in this paper"

- Funding: No funds, grants, or other support was received

- Competing interests: The authors declare no competing interests.

\section{References}

1. Blaha F, Langenecker B (1955) Dehnung von zink-kristallen unter ultraschalleinwirkung. Naturwissenschaften 42(20):556-556

2. Balamuth L, "Progress in Ultrasonic Metal Forming," 1965

3. Spur G, Holl SE (1996) Ultrasonic assisted grinding of ceramics. J Mater Process Technol 62(4):287293 1996/12/01/,",",

4. Amini S, Hosseinpour A, Gollo, Paktinat H, "An investigation of conventional and ultrasonic-assisted incremental forming of annealed AA1050 sheet," The International Journal of Advanced Manufacturing Technology, vol. 90, no. 5, pp. 1569-1578, 2017/05/01, 2017

5. Rasoli MA, Abdullah A, Farzin M, Tehrani AF, Taherizadeh A (2012) Influence of ultrasonic vibrations on tube spinning process. J Mater Process Technol 212(6):1443-1452 2012/06/01/, ",,",

6. Hernández-Ortega JJ, Zamora R, López J, Faura F, "Analysis of vacuum melting, ultrasonic, and radiographic techniques for gas porosity evaluation in die castings," The International Journal of Advanced Manufacturing Technology, vol. 67, no. 1, pp. 745-757, 2013/07/01, 2013 
7. Tabatabaei SMK, Behbahani S, Mirian SM, "Analysis of ultrasonic assisted machining (UAM) on regenerative chatter in turning," Journal of Materials Processing Technology, vol. 213, no. 3, pp. 418425, 2013/03/01/, 2013

8. Culp DR, Gencsoy HT, "Metal Deformation with Ultrasound." pp. 195-198

9. Chen G, Ren C, Yang X, Jin X, Guo T, "Finite element simulation of high-speed machining of titanium alloy (Ti-6Al-4V) based on ductile failure model," The International Journal of Advanced Manufacturing Technology, vol. 56, no. 9, pp. 1027-1038, 2011/10/01, 2011

10. Fan G, Sun F, Meng X, Gao L, Tong G (2010) Electric hot incremental forming of Ti-6Al-4V titanium sheet. The International Journal of Advanced Manufacturing Technology 49:no. 9-12, ", , , pp. $941-$ 947

11. Najafabady SA, Ghaei A (2016) An experimental study on dimensional accuracy, surface quality, and hardness of Ti-6Al-4 V titanium alloy sheet in hot incremental forming. The International Journal of Advanced Manufacturing Technology 87:no. 9-12, “,”, , pp. 3579-3588

12. Tian B, Chen F, Tong YX, Li L, Zheng YF, Liu Y, Li QZ, "Phase transition of Ni-Mn-Ga alloy powders prepared by vibration ball milling," Journal of Alloys and Compounds, vol. 509, no. 13, pp. 45634568, 2011/03/31/, 2011

13. Zhao C, Li H, Jiang J, He Y, Liang W, “Phase Transition and vibration properties of MnCO3 at high pressure and high-temperature by Raman spectroscopy," High Pressure Research, vol. 38, no. 3, pp. 212-223, 2018/07/03, 2018

\section{Figures}
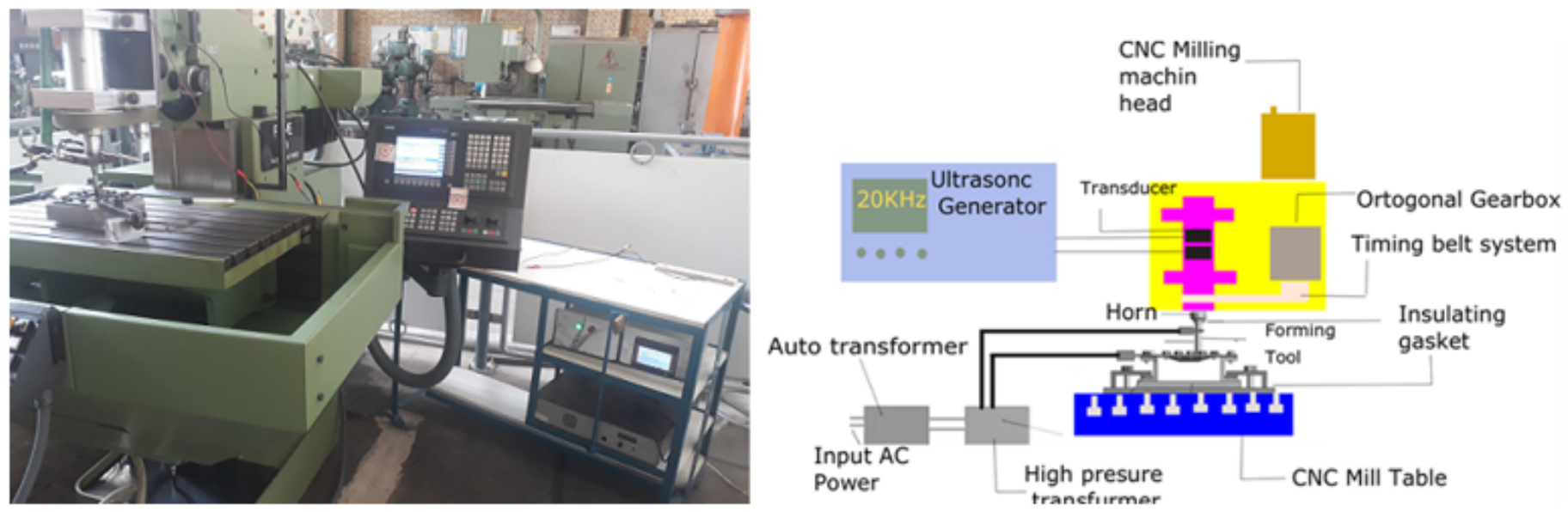

Figure 1

Schematic illustration of HEIF process with ultrasonic-assistant 

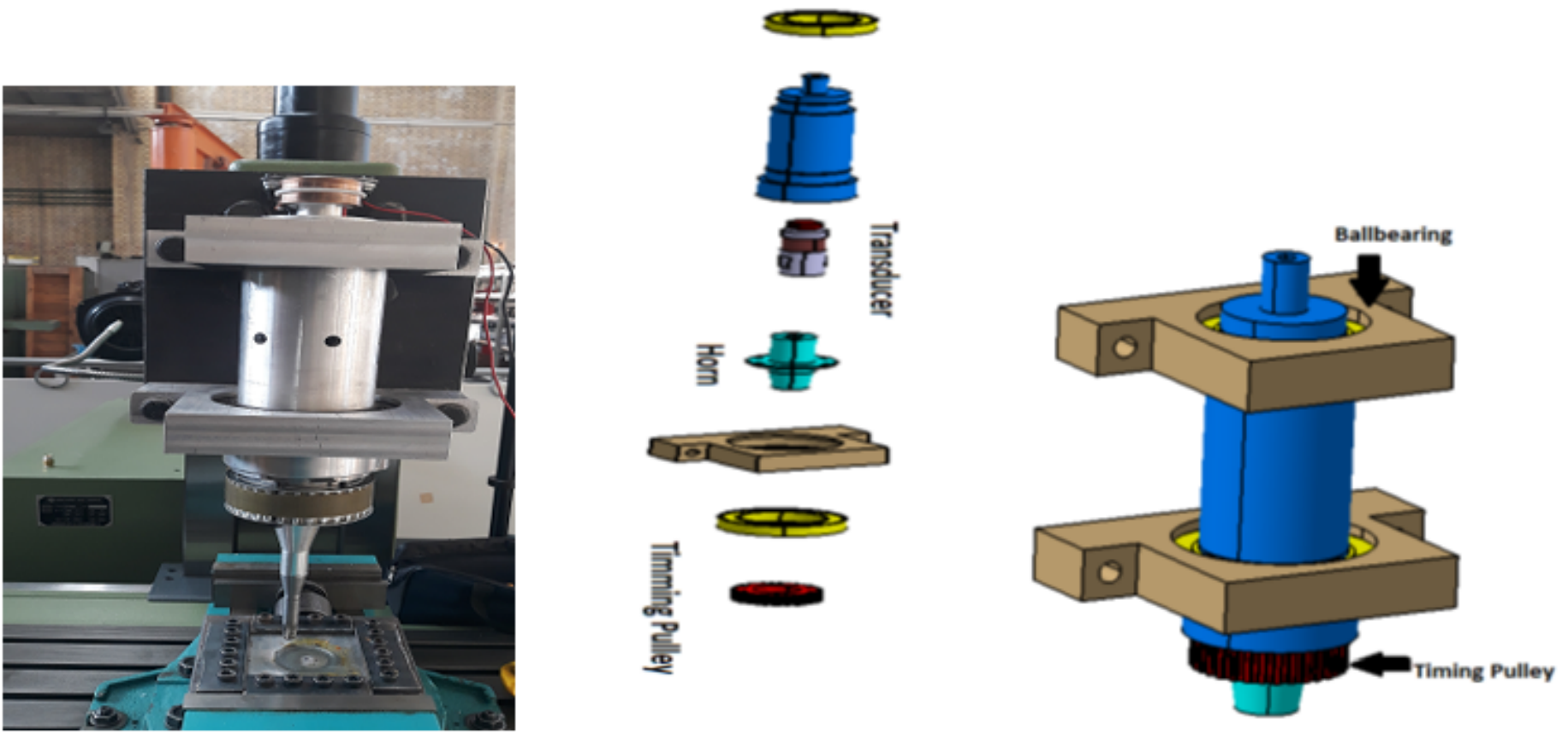

Figure 2

Transmission system was used to transmit the torque from spindle to transducer

\begin{tabular}{|c|c|c|c|c|}
\hline \multicolumn{3}{|c|}{ 으 Step/Frame } & $x$ & 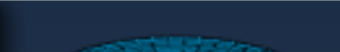 \\
\hline \multicolumn{2}{|c|}{ Step Name } & Description & & \\
\hline \multicolumn{4}{|l|}{ Step-1 } & \\
\hline \multicolumn{4}{|l|}{ Frame } & \\
\hline \multicolumn{4}{|c|}{ Index Description } & \\
\hline 0 & Increment & 0: Base State & Close & \\
\hline 1 & Mode & 1: Value $=1.67557 \mathrm{E}+10$ Freq $=20602$ & (cycles/time) & \\
\hline 2 & Mode & $2:$ Value $=1.90441 \mathrm{E}+10$ Freq $=21963$ & (cycles/time) & \\
\hline \multicolumn{4}{|c|}{ 3: Value $=1.90441 \mathrm{E}+10 \mathrm{Freq}=21963 . \quad($ cycles $/$ time $)$} & \\
\hline & $\square$ & Field Output... & Cancel & \\
\hline
\end{tabular}

\section{Figure 3}

Result of Modal analysis 


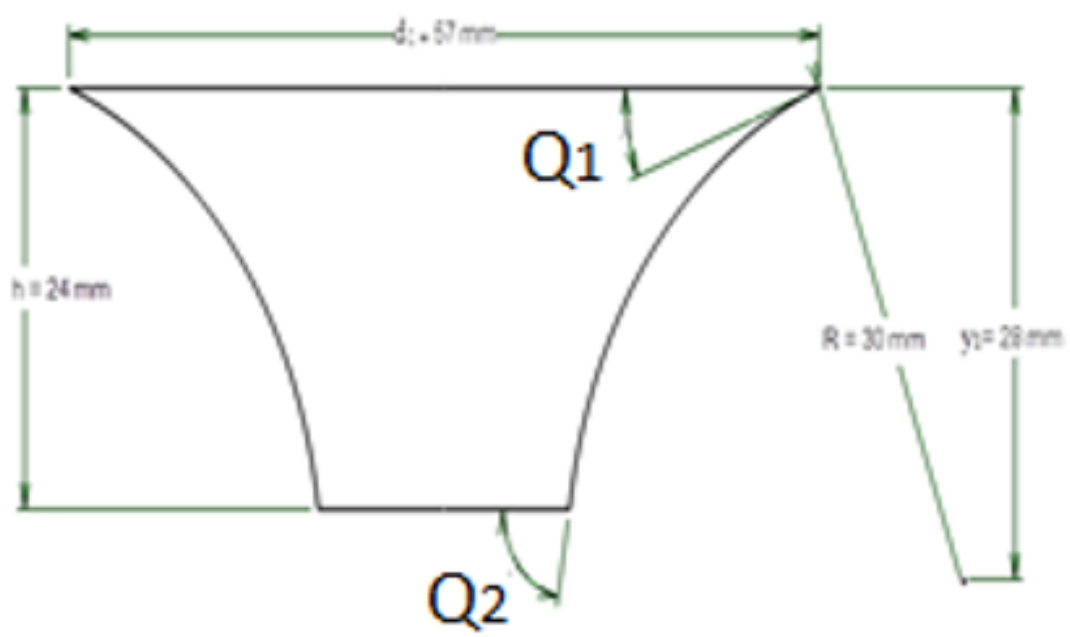

Figure 4

Cross-section of the geometry specimen

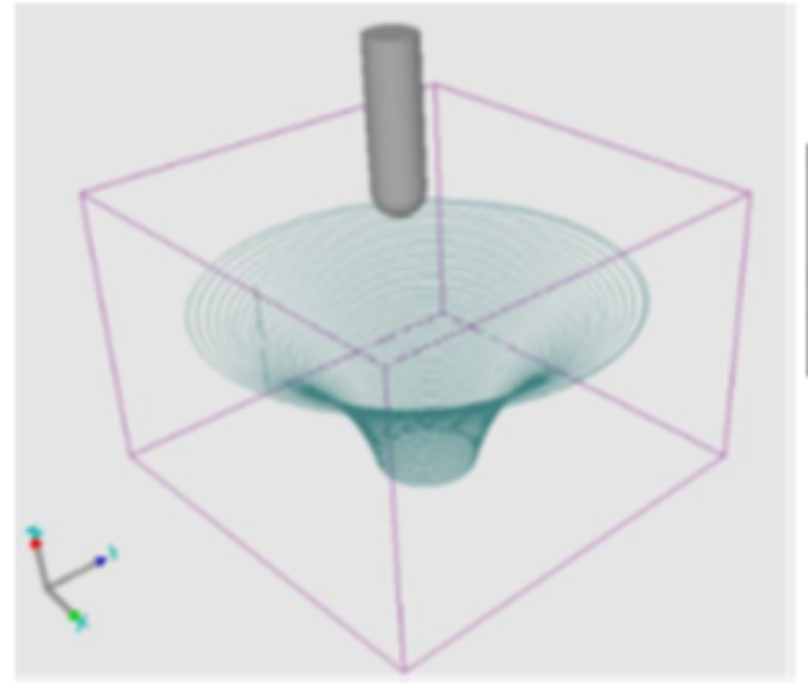

(a)

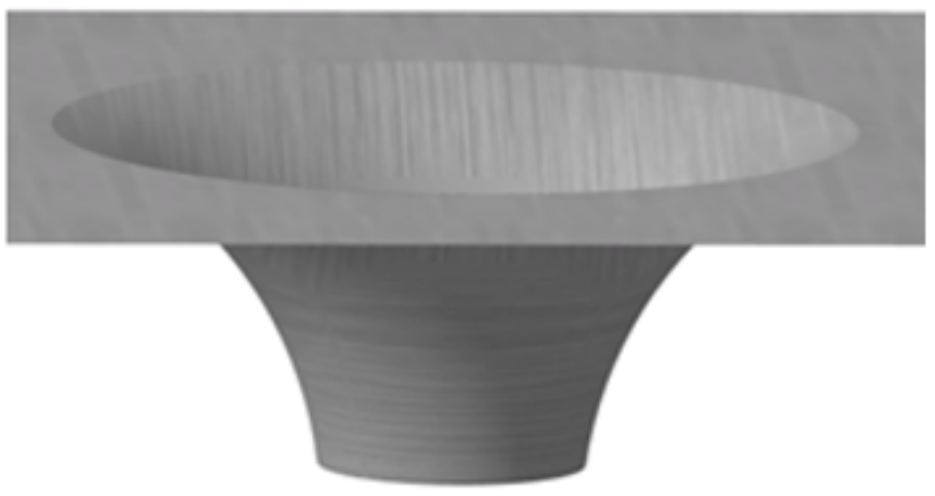

(b)

Figure 5

(a) forming toolpath (b) photograph of the formed workpieces 


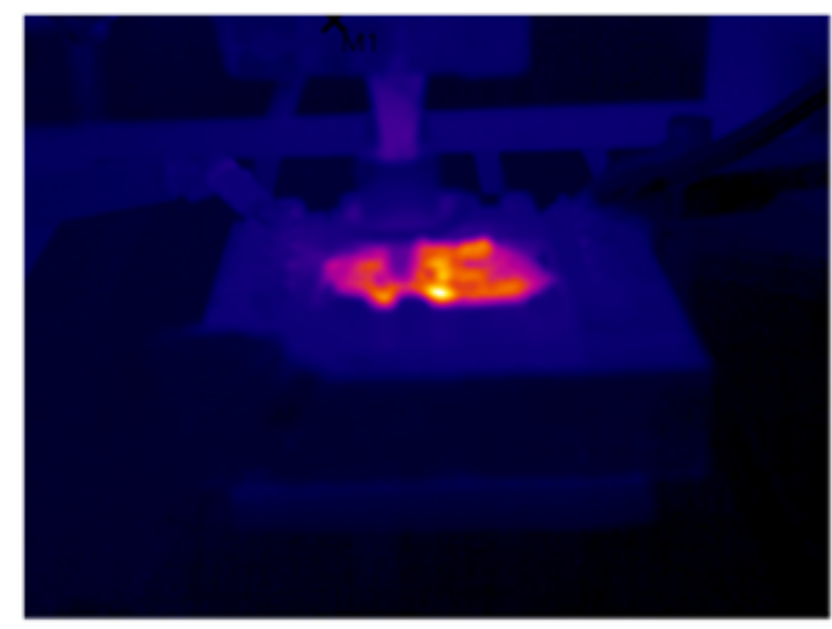

(a)

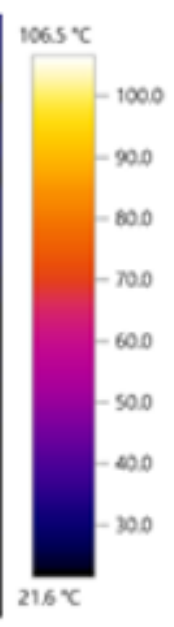

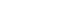

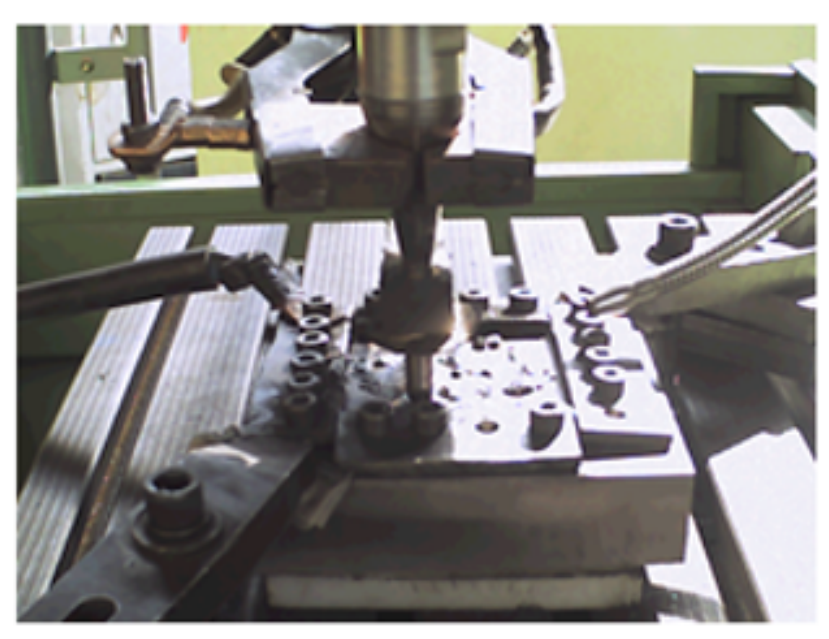

(b)

\section{Figure 6}

(a) Thermograms of ultrasonic heat effect with no Ohm effect (b) The same photo by normal camera

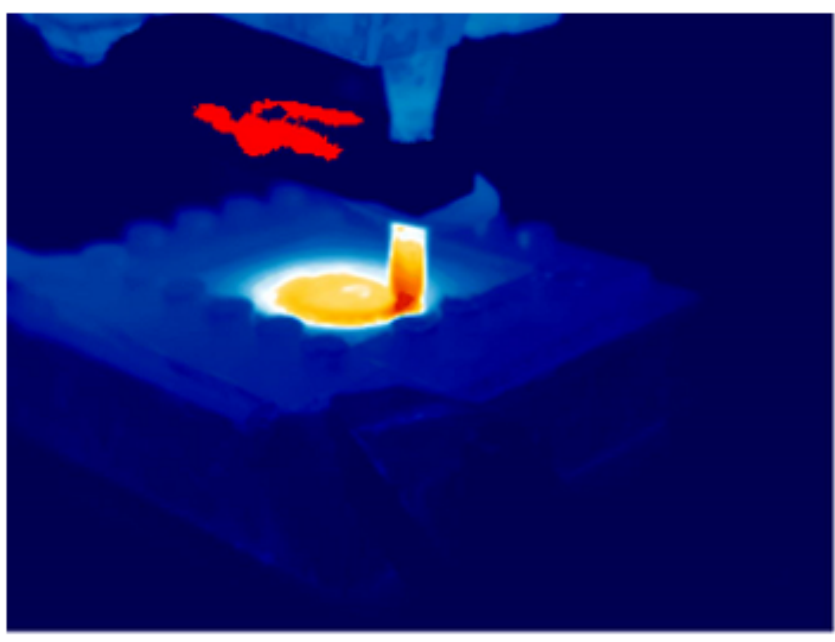

(a)

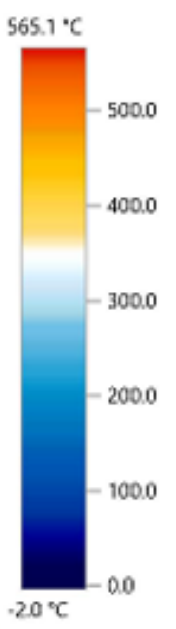

$-20^{\circ} \mathrm{C}$

(1)

\section{Figure 7}

(a) Thermograms of the EHIF with ultrasonic-assistant (b) The same photo by normal camera 


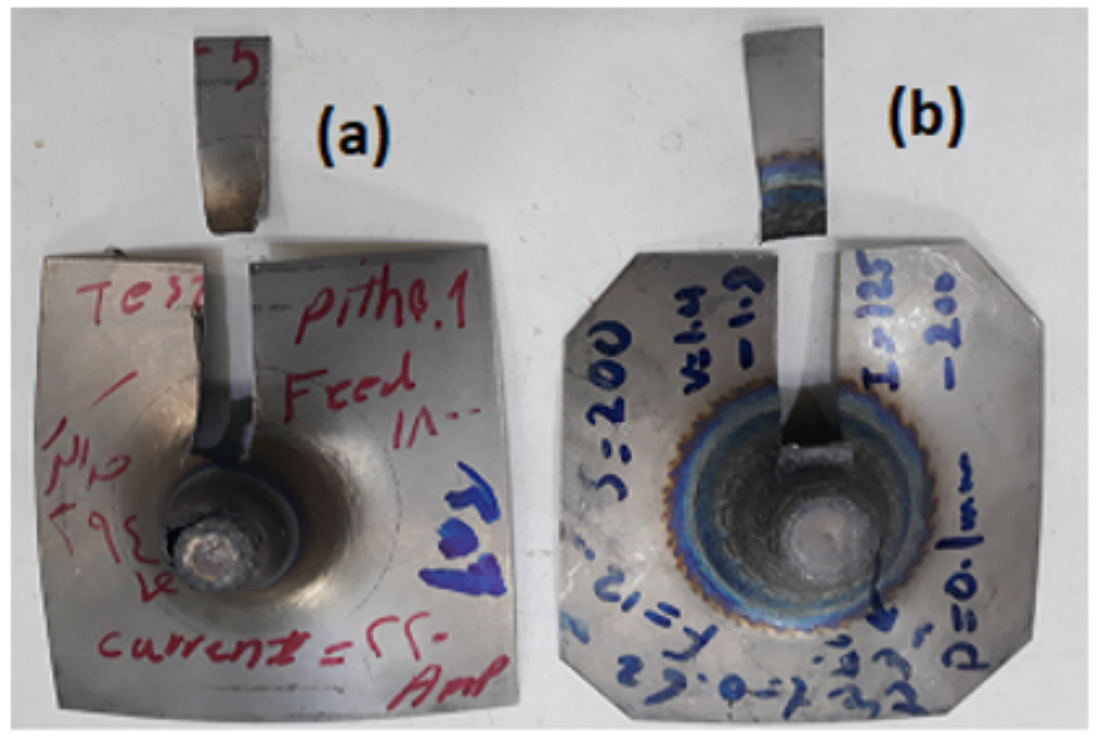

Figure 8

Formed specimen with EHIF (a) With ultrasonic-assistant (b) without ultrasonic-effect

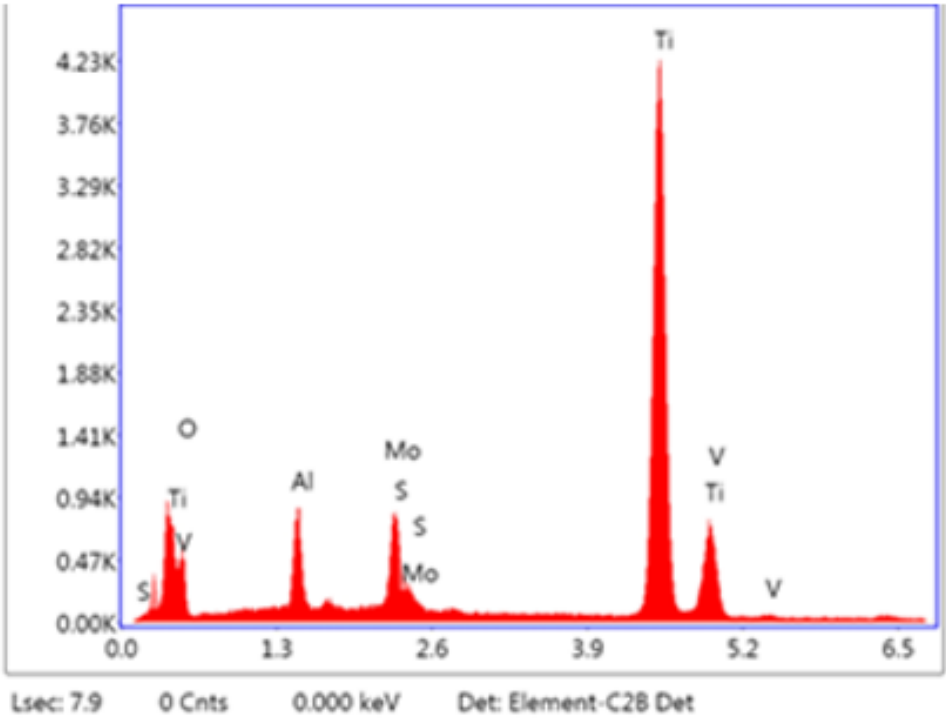

(a)

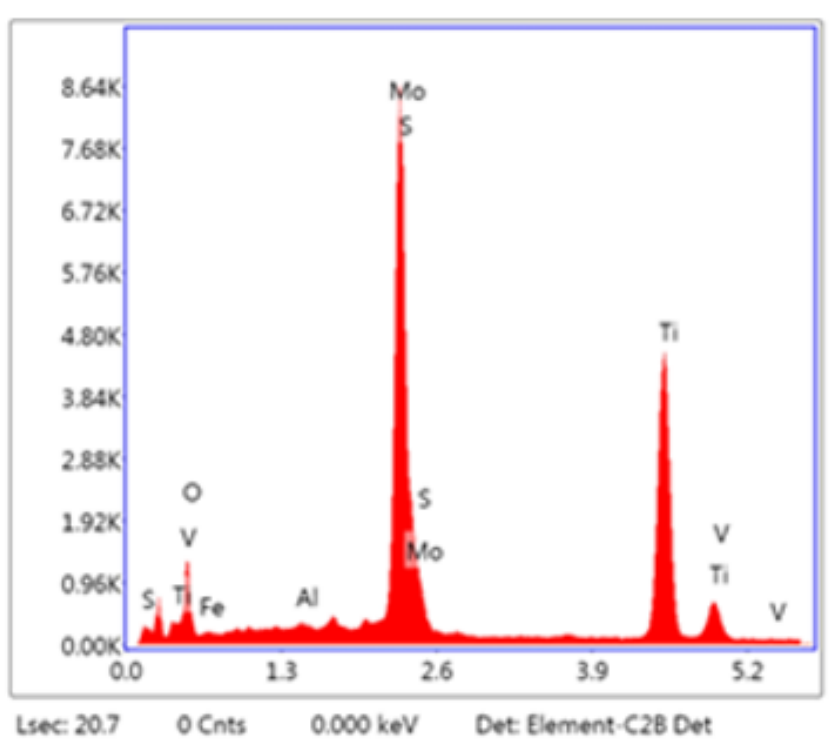

(b)

Figure 9

Result of EDAX analysis, (a). EHIF with ultrasonic-assisted, (b). EHIF without ultrasonic-effect 


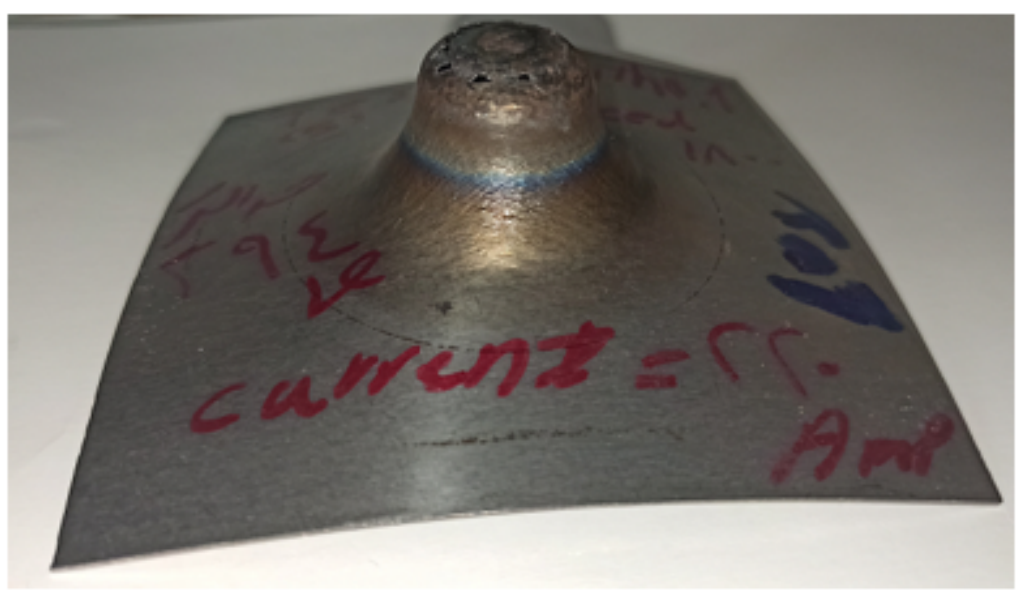

Figure 10

Shows specimen that formed completely but is defected because of heat accumulation

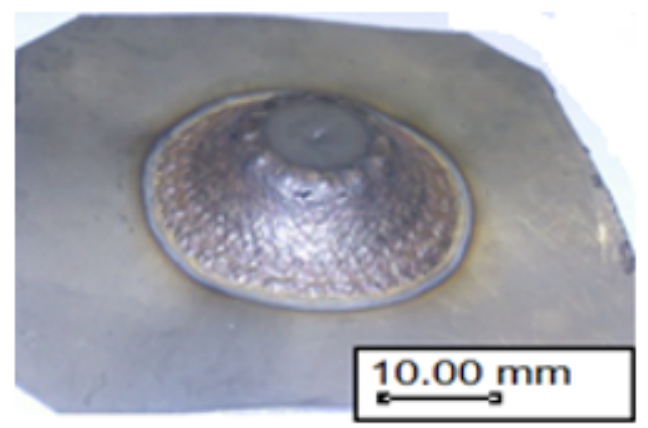

(a)

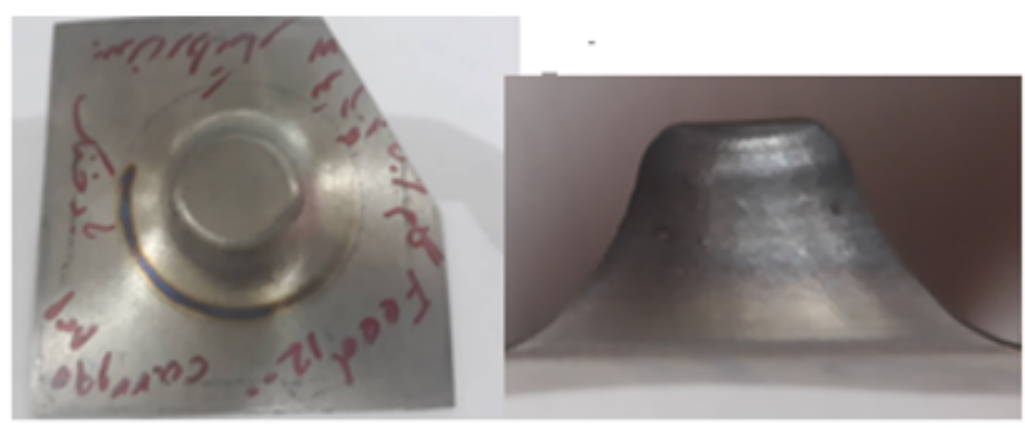

(b)

\section{Figure 11}

Comparison quality surface, (a) product with EIHF (b)product with EHIF ultrasonic-assistant 


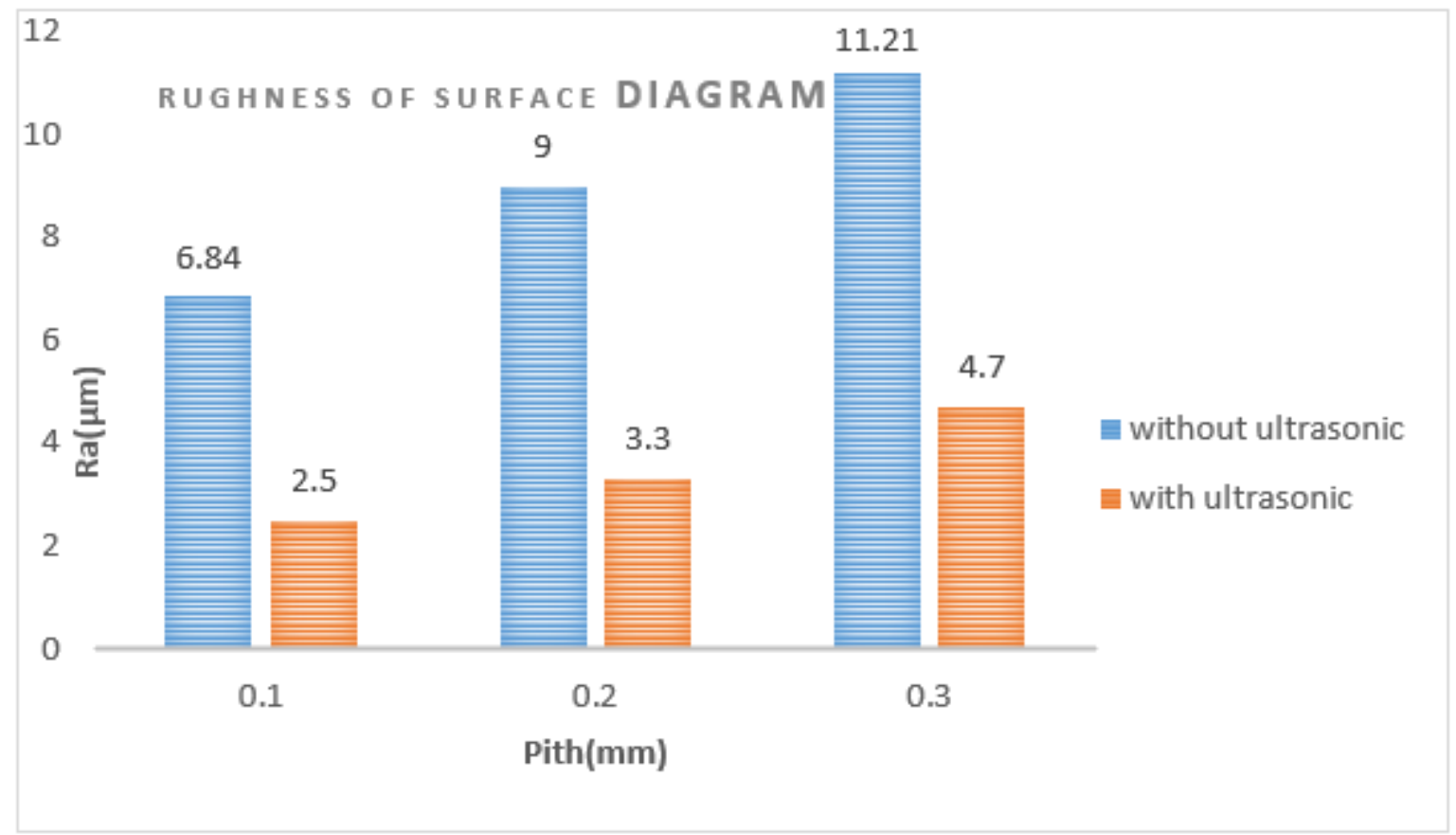

Figure 12

Comparison of the average surface roughness

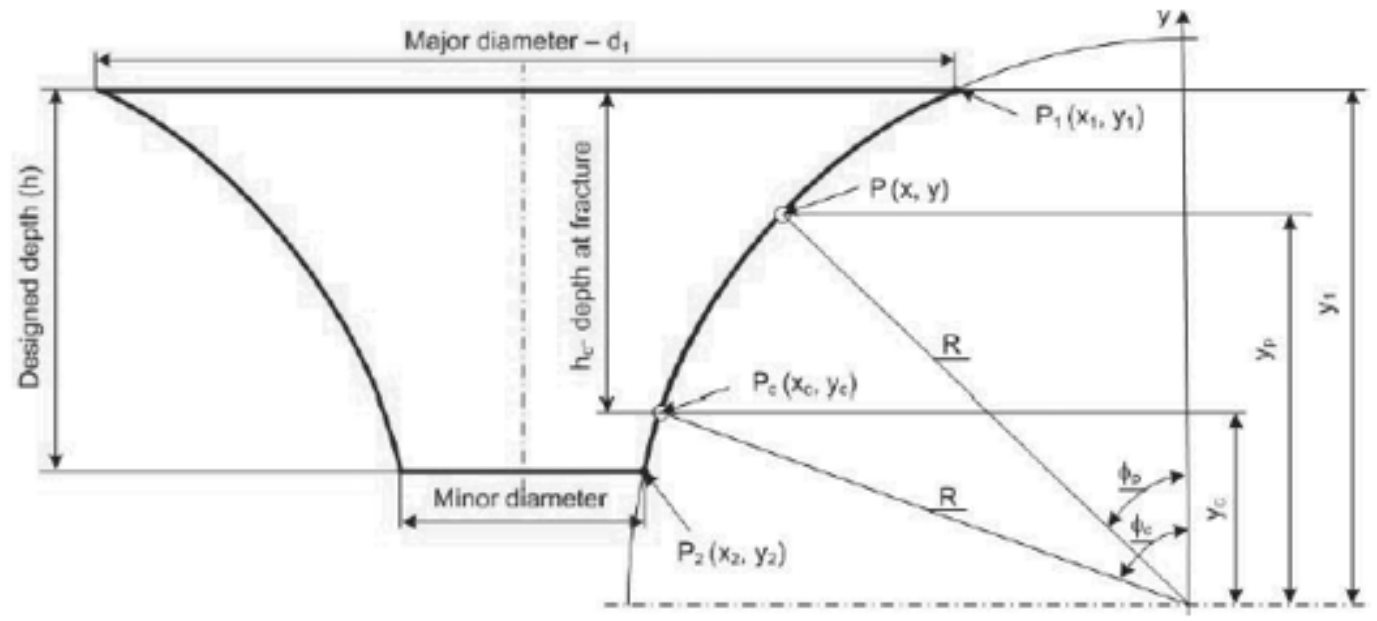

Figure 13

Desier geometery of work picece 


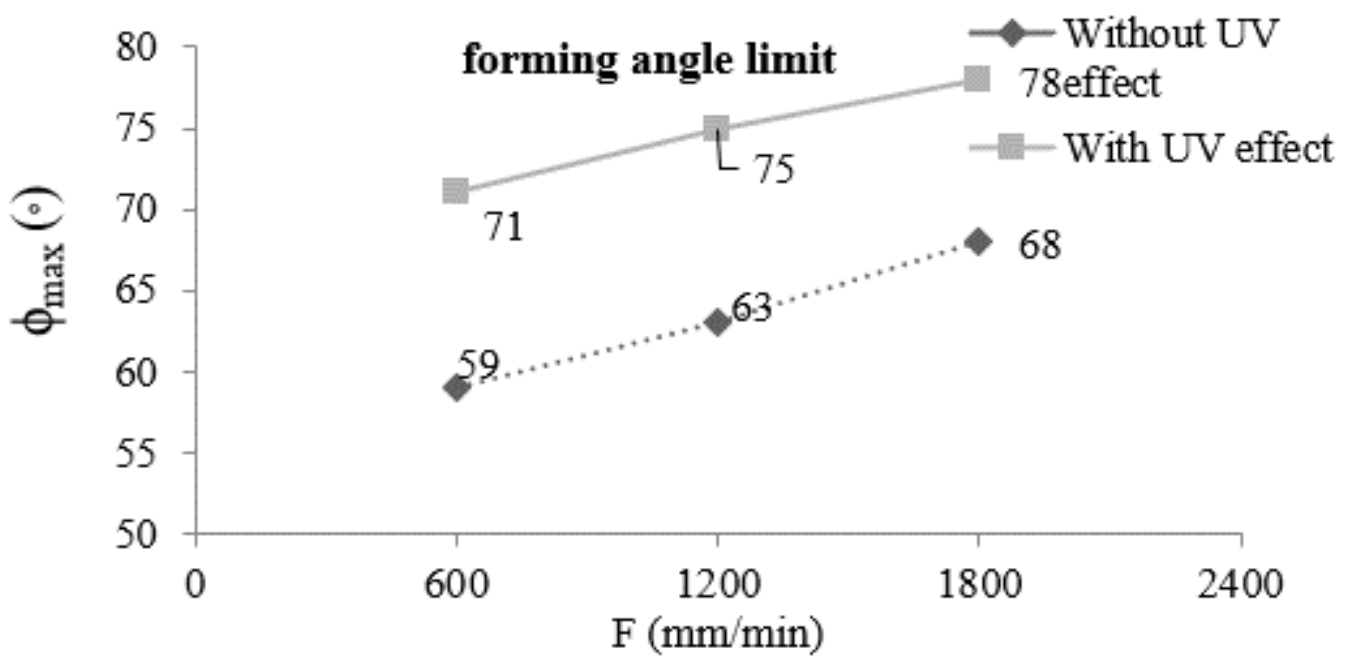

\section{Figure 14}

Comparison of ultrasonic and feed-rate effect on forming angle

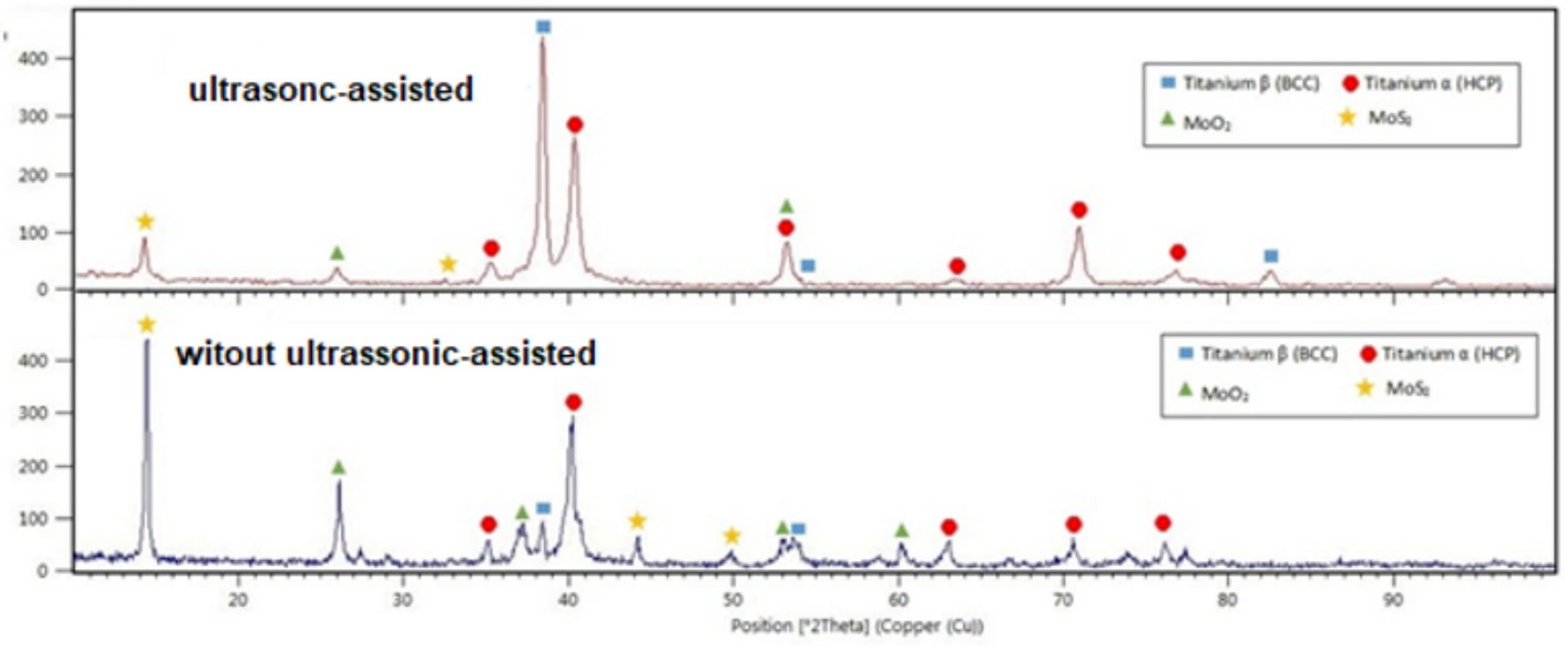

Figure 15

XRD phasis analysis show that $\beta$ phasis (BCC structure) increases significantly with ultrasonic-assisted 